\title{
Climate forcing on millennial, orbital and million year scales: a case study from the Toarcian Oceanic Anoxic Event
}

DAVID B. KEMP ${ }^{1 *}$, KENTARO IZUMI ${ }^{2}$, WENHAN CHEN ${ }^{1}$, SIMIN JIN ${ }^{1}$, WESLEY T. FRASER ${ }^{3}$

${ }^{1}$ State Key Laboratory of Biogeology and Environmental Geology and School of Earth Sciences, China University of Geosciences (Wuhan), 388 Lumo Road, Wuhan, P.R. China (*correspondence: davidkemp@cug.edu.cn)

${ }^{2}$ Faculty \& Graduate School of Education, Chiba University, 1-33 Yayoi-cho, Inage-ku, Chiba-shi, Chiba, Japan

${ }^{3}$ Geography, Faculty of Humanities and Social Sciences, Oxford Brookes University, Oxford, UK

The early Toarcian Oceanic Anoxic Event (T-OAE, 182 $\mathrm{Ma}$ ) was a significant perturbation to the global carbon cycle. A range of severe environmental changes have been linked to this event, including: climate warming, mass extinction, ocean deoxygenation, and an increase in hydrological cycling. A negative carbon-isotope excursion (CIE) affecting marine and terrestrial carbon reservoirs accompanied these phenomena, and has been linked to the release of large volumes of ${ }^{12} \mathrm{C}$-enriched carbon. Long-term $\mathrm{CO}_{2}$ effusion from volcanism associated with the break-up of Pangea likely played a key role in triggering this CIE and the broader environmental changes. Nevertheless, the precise pattern, duration and pace of carbon release is unclear.

A review of carbon-isotope data from $>60$ T-OAE sections helps to reconcile uncertainties in the pattern, duration and magnitude of the CIE. When sampled at sufficiently high resolution, sections worldwide demonstrate that a long-term $\left(10^{5}\right.$ year $)$ decline to minimum carbonisotope values was punctuated by much more abrupt negative shifts, each of which can be linked to discrete pulses of carbon release paced by orbital forcing. New carbon-isotope data collected at $\mathrm{mm}$ - to $\mathrm{cm}$-scale resolution from sedimentary sections in Japan and UK demonstrate that the timescale of these carbon release events spanned no more than a few thousand years each.

The rapidity of carbon release during the T-OAE was extreme in the context of the overall duration of the event and the protracted environmental changes associated with it. Nevertheless, isotope mass balance calculations indicate that maximum rates of carbon release and consequent $\mathrm{CO}_{2}$ change were almost certainly slower than modern rates linked to anthropogenic carbon emissions. 